\title{
OSA Optics Discovery Kit: its development and use
}

\section{Donald O'Shea}

Donald C. O'Shea, "OSA Optics Discovery Kit: its development and use," Proc. SPIE 1603, Education in Optics, (1 March 1992); doi: 10.1117/12.57867 


\title{
The OSA Optics Discovery Kit-its development and use
}

\author{
Donald C. O'Shea \\ Georgia Institute of Technology, Center for Optical Science and Engineering \\ School of Physics, Atlanta, GA 30332-0430
}

\begin{abstract}
This is a description of a project in elementary school optics education that originated through a professional society, the Optical Society of America (OSA). The purpose of this paper is to show how the project was started, the process by which the OSA Optics Discovery Kit was finally produced and distributed, and the current efforts to use the kits and to extend the idea to other educational levels. Through this discussion it is hoped that others may find both description of the kit and its generation of use in their efforts to engage the interest of youth in science.
\end{abstract}

\section{INTRODUCTION}

My first contact with optics came through the simple Japanese telescopes that I used to buy after World War II. At that time the optics industry of Japan was not noted for the quality of the cameras and camcorders that it is justly famous for today, but for the low cost and lack of durability of its products. I became interested in optics and lenses, because my cheap Japanese telescopes used to fall apart after some time. When the plastic barrel cracked on the toy telescope I salvaged the lenses and discovered something about lenses and light. Over time I collected a series of lenses and mirrors in a cigar box to be used for my experiments in optics.

My second contact with optics came from being hit by a car. It happened to be the headlight, but that's not the optics contact I am referring to. Rather, during my stay in the hospital, an aunt brought me the first copy of the Scientific American I had ever seen. There were two things that I remember from that issue and both were advertisements. One was for a Questar telescope. What particularly impressed me was that the telescope cost as much as the price of a good size car at the time. Obviously there was more to optics than my toy telescopes. The other was an ad for Edmund Salvage Company, a company that sold salvaged war parts, many of them optical components. But Edmund went beyond simply salvaging optics, because they also included simple plans for making optical instruments such as opaque projectors and telescopes with their components. A large number of professional and amateur astronomers got started by purchasing the blanks, grits, and eyepieces from Edmund. Certainly the ability to buy inexpensive lenses and other optics parts was contributed to my own interest in optics and lasers.

Later, this interest was converted to a professional activity as a teacher of optics at Georgia Tech. It gave me the chance to transmit that interest in others. I have always believed that you have to see or work with something to truly understand it. I remember a fellow graduate student at Johns Hopkins who had been calculating line strengths for several months as part of his thesis work, when he walked into our lab, and saw an atomic line spectrum for the first time! So when I began to organize a short course on laser system design for the University of Wisconsin's Extension program and I would not have the benefit of a teaching laboratory nearby, I wanted to be able to place into the hands of the students some optics components that would given them a better sense of the field. At that time there was a packet of components that could be purchased as part of the Berkeley physics series, a sequence of undergraduate texts that included the direct experience of the student as a necessary part of the curriculum. The packet contained a series of polarizers and wave plates, a diffraction grating and color filters. The entire package, which is not longer available, was only a little bigger and bulkier than a large tea bag. I mention the above items since all contributed to the generation of the OSA Optics Discovery Kit. 


\section{OSA EDUCATION COUNCIL}

With the publication of several studies that indicated that American students were neither interested in nor equipped to study science and mathematics, the Optical Society of America, a non-profit professional organization, established an education committee and charged them with developing projects that would assist both the members and the general public in the teaching and the promotion of optics as a profession. In the initial discussions there was always the question: Where are the optical scientists and engineers of the 21st century going to come from?

Within the span of two years the committee established a number of education projects that has led professional societies in the field. Perhaps the most successful has been the Educators' day held at the Annual Meeting of the Society. Working with the science administrators for the state educational systems in the states or provinces near the site of the Annual Meeting, the Society invites as honored guests a select group of teachers from all levels of precollege education to the Annual Meeting. During one day of the meeting, designated Educators' Day, the Society provides special lectures on various aspects of optics, conducts a number of workshops for the teachers, and has them tour the technical exhibition that accompanies the conference. The schedule for the last Educators' Day is reproduced in Table 1. The lecturers have been many of the Society's most illustrious members including Professor Arthur Schawlow, the Nobel laureate, who gave one of the most delightful talks I have ever heard.

Table 1. List of events for the 1990 Educators' Day at the Annual Meeting of the OSA held on November 6, 1990 in Boston, Massachusetts.

\begin{tabular}{|l|l|}
\hline Time & Event \\
8:00 AM & Continental Breakfast and Registration \\
9asement-Floor Holography and Beyond \\
9:50-10:05 AM & $\begin{array}{l}\text { Steven Benton, MIT Media Laboratory } \\
\text { 10:10 AM }\end{array}$ \\
& $\begin{array}{l}\text { Coffee Break } \\
\text { 11:00 AM }\end{array}$ \\
12:00 N & David Williams, Center for Visual Science, University of Rochester \\
1:00 PM & Lunchit Hall Tour \\
& What Do Laser People Do, and Why Do They Do It? \\
2:00 PM & Elsa M. Garmire, Center for Laser Studies, University of Southern California \\
& Holography Demonstration \\
3:30 and & Tung Jeong, Lake Forest College \\
4:30 PM & Hands-On Optics Kit Workshop \\
Donald O'Shea, Georgia Tech and David Stork, Stanford University \\
3:30 and & Fun with Photonics! Optics in Toys and Consumer Products \\
4:30 PM & Stephen D. Fantone, Optikos Corporation \\
5:30 PM & Reception \\
6:30 PM & Adjournment \\
\hline
\end{tabular}

Other projects established by the Education Committee include an OSA Summer Fellow, education grants for elementary and high school teachers, an education column in the OSA magazine, Optics and Photonics News, a graduate student seminar at the Annual Meeting, a database of optics education in the United States and Canada, and resources for education in optics. After a number of years, the Committee was elevated to one of the four Councils of OSA in recognition of the role that these projects played in the overall activities of the Society. The resource subcommittee of the Education Council was organized to look into methods of providing students and teachers with the tools needed to promote interest in science in general and optics in particular. As chair of the subcommittee I decided to investigate the possibility of providing optical components for students and teachers. My ideas grew out of my earlier experiences with cheap lenses, optics with instructions to build instruments, and the compact little packet of the Berkeley Physics Series. In order to assure that we were not duplicating other efforts, I wrote to a number of possible sources and visited some science museums, since these institutions would be a potential point of distributions for such kits. I found nothing that approximated the type of low cost kit that I envisioned. 


\section{THE OSA OPTICS DISCOVERY KIT}

At the outset, my concept was an optics junkshop: a collection of a number of optical components that a child could play with. Part of it came from my own cigar box of lenses, part from the optics packet that $I$ had been using in the short course. The emphasis was and has remained on discovery rather than formal teaching. That doesn't mean, however, that the kit cannot and has not been used as part of established teaching programs.

The first consideration was the contents of the kit. I felt that we had to have lenses. So I went to my first source of cheap lenses: Edmund Salvage, now called Edmund Scientific. But the world had changed and everything was more costly. Also the lenses were all glass. Was it possible to find something cheaper in plastic? I was eventually put in touch people at United Lens, one of the largest manufacturers of plastic optics in the world. The gentleman I talked to agreed to send me a number of his stock lenses. As I remember it, he mentioned offhandedly that he had a set of lenses that once was used in an educational kit many years ago, but that the moulds had been abandoned. Should he send them to me? Sure, it wouldn't hurt, I think I said.

When I first saw this set of lenses, I knew we had an optics kit. There are three lenses in the set, two positive lenses, one short focal length lens and one long one, and a negative lens. The lenses are centered in a tablet shaped like a tombstone. The tablet has a ridge around the edge that protects the lens surface when it is laid on a flat surface. The tablet design is particularly useful for children since anyone not familiar to optics tends to pick up a lens in the middle rather than holding it by its edges.

Some of the other components components for the kit (Fig. 1) are obvious choices: a diffraction grating, two polarizers, four color filters. Other choices were a matter of opportunity or luck. I wanted a Fresnel lens for the kit, but the ones I could find were too expensive for the kit. Another member of the Education Council, Helen Gourley suggested that I call Dr. Richard Claytor of Fresnel Technology. He has a lens that was usually moulded into the top of boxes for holding insects. Through Dr. Claytor we were able to purchase the "bug box lens" at a price comparable to the other components in the kit. This same cooperation with different suppliers in the optics industry was shown by Polaroid when obtaining polarizers and the extremely bright Mirage holograms. Polaroid has donated all 15,000 holograms used in the kits thus far. This is also true of the optical fiber included in the kits. We are indebted to Ensign-Bickford for donating $15 \mathrm{~km}$ of fiber for the kits. I wanted a mirror in the kit, but a shiny flat mirror might be either too fragile if made of glass or easily destroyed if made of a metal. A curved mirror of any material would be too expensive. I decided on a flexible plastic mirror because it would be fun to play with and it was cheap. It could be used as a sort of portable fun-house mirror. The color filters are standard gel filters from a theatrical supply house and the diffraction grating was purchased from my old optics source, Edmund Scientific.

There were some optical components that were not included in the kit. For example, some of the components in the Berkeley physics kit, the half- and quarter-wave plates as well as their combination with polarizers that produced a circular polarizer and a polarization rotator, were not included. I felt that these components, while providing interesting effects would confuse someone beginning in optics. One suggestion that kept coming up and I kept rejecting was to add a prism to the kit. To counter these suggestions, I devised the quarter-inch rule, which said that no component in the kit could be more than a quarter-inch thick. The real reason for rejecting a prism is that it is glass (good plastic prisms are difficult to make and the dispersion is small) and therefore expensive for any reasonable size. In addition, it is difficult to produce a spectrum with a small prism - even for adults. The quarter-inch rule also kept the size of the components manageable and easy to package.

\section{THE EXPERIMENTS}

While it would be nice to think that putting these components in the hands of a kid would result in an immediate appreciation of optics, it is more likely that most children would find the items mildly interesting, but would not know what to do with them. To this end a set of short experiments were devised to illustrate the use of the items in the kit. None of the experiments is very difficult or elaborate. This is, after all, intended as a discovery kit. The description of the experiments was modeled after the simple displays used in conjunction with the exhibits at the Exploratorium science 


\section{ITEMS IN THE OSA OPTICS KIT}

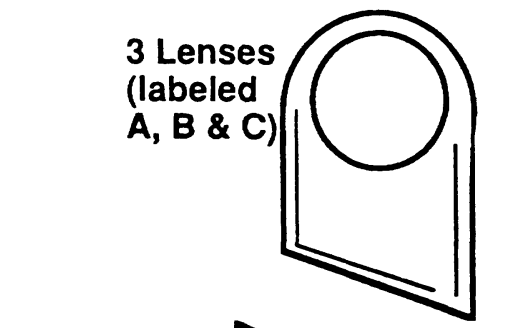

(remove paper

coating)

Fresnel Lens

(flat piece of

plastic with

circular ridges)
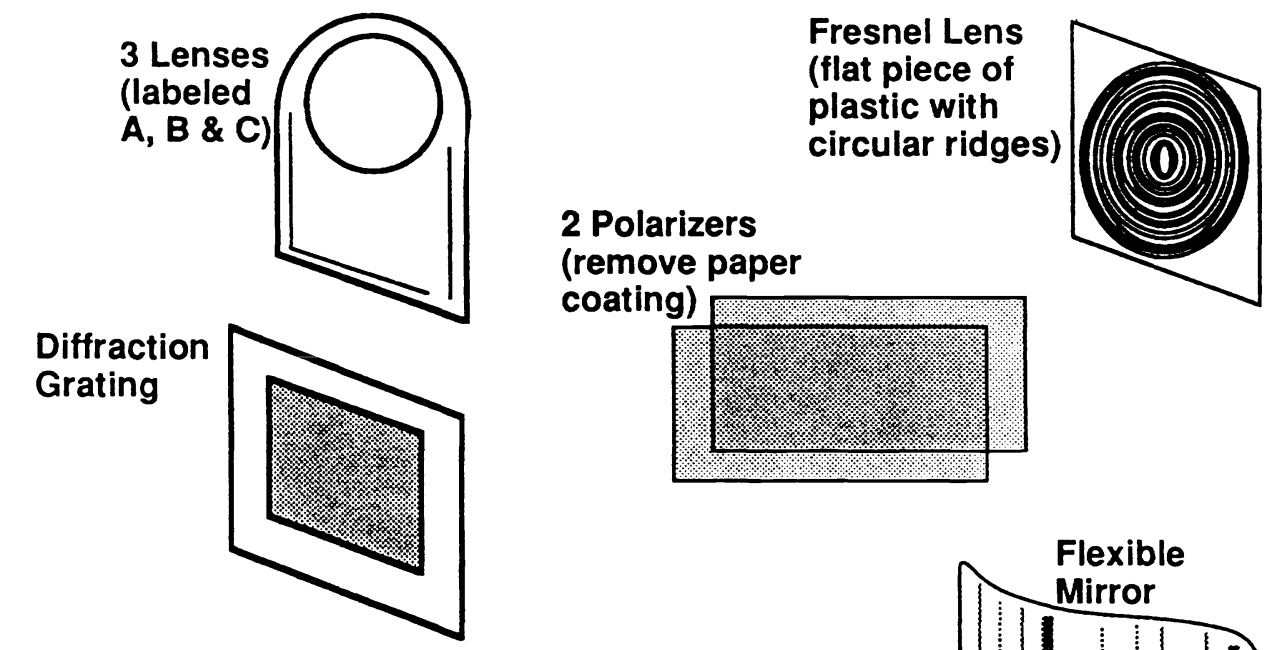

Optical Fiber
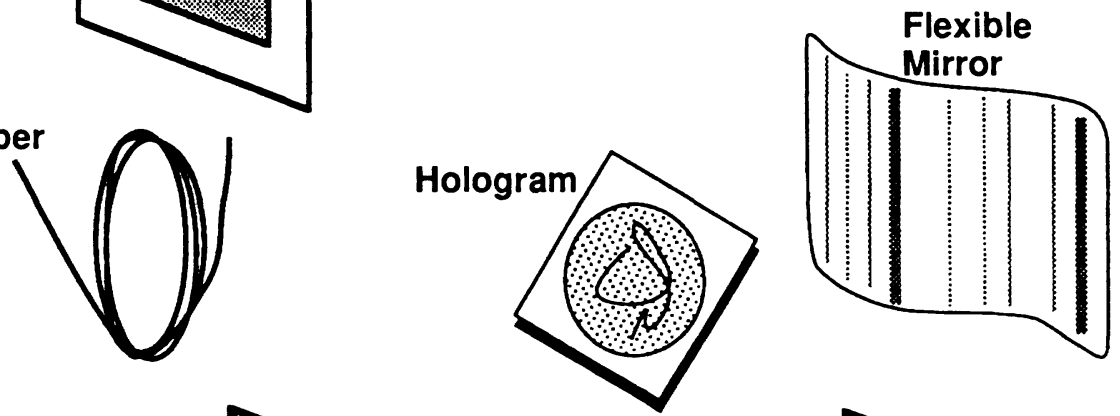

Color filters (red, yellow, green, \& blue)
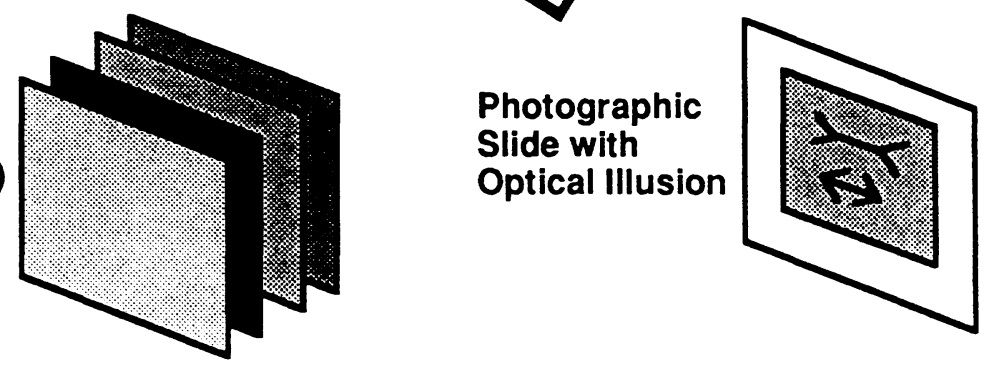

ADDITIONAL MATERIALS NEEDED: White card, Ruler, Flashlight, Tablespoon, Small light with unfrosted bulb, and a Piece of transparent, stretchable plastic.

\section{CAUTION!}

Some of these items are made for you to look through. However, you should never look at the sun directly or at the sun through any of these items.

Fig. 1. Components of the OSA Optics Discovery Kit. Illustration is part of the Student Experiments pages in the Classroom Kit. 
museum in San Francisco. The items needed for the experiment are listed above a diagram of it. Below is a simple description of the actions to be carried out and a short list of questions to guide the user in their discovery. This is followed by an explanation of the experiment without using equations and a short note on how the components are useful in daily life or important for new technology. The format is shown in Fig. 2 and a list of the experiments is given in Table 2.

Table 2. List of Experiments in the OSA Optics Discovery Kit

\begin{tabular}{l|l|} 
1. Lenses. & Observation of images and measurement of focal length. \\
2. Magnifiers. & Use of positive lenses as magnifiers. \\
3. Galilean Telescope. & Location of two lenses to make a telescope and observation of image. \\
4. Keplerian Telescope. & Similar to Expt. 3 with a different eyepiece lens. \\
5. Fresnel Lens. & Similar to Expt. 1 using a Fresnel lens. \\
6. Projector. & Projection of images using a light bulb, a slide, and one of the positive lenses. \\
7. Diffraction Grating. & Observation of white light spectrum and effects of color filters. \\
8. Polarizers. & Use of crossed polarizers, polarization by reflection, stress birefringence. \\
9. Mirrors. & Images created using a bendable mirror, real image using the bowl of a spoon. \\
10. Holograms. & Observation of a reflection-type white light hologram. \\
11. Fiber Optics. & Transmission of light through 1 meter of optical fiber.
\end{tabular}

Shortly after the kits were introduced our first OSA Summer Fellow, George Smeller, a high school teacher, noted that many teachers, being unfamiliar with the field of optics, might buy the kits or have them given to them, but unless there was additional information to help them conduct these discovery experiments, the teachers would feel unprepared and might not use the kits. This became known as "The Problem of the Back Shelf." That is, we did not want to see these kits that we had worked hard to create end up on the back shelf of a classroom never to be used again. To this end George developed a teacher's manual to be used with the kits. Each student experiment page was followed by a teacher's section divided into four short parts. The first, Notes on Set-up, was intended to give basic information on the optimal classroom conditions for the experiment. The second, Expected Results, answers the questions raised in the activities section of the experiment sheet. The third section, Discussion Questions, is intended to take the experiment beyond the experiment sheet. Finally, there is a list of Additional Activities for More Advanced Students. An example of one of the experiments in the teacher's manual is given in Fig. 3. In the manual we did break the no-equation rule, but only once, for the thin lens equation.

\section{DISTRIBUTING THE KIT}

Getting the kits into production took a good deal of telephoning, writing, and and a certain amount of what can only be called hustling. Lining up suppliers, establishing delivery dates, negotiating a few cents off each component were all part of producing the first set of kits. We wanted to use the kits for Educators' day. Even though we started with what seemed like an enormous lead time, getting the lenses and other components took much longer that expected and we finished just in time. The first kits were assembled in plastic Baggies in my laboratory with the help of some of my graduate students. For Educators' day each teacher was given a kit, a set of the experiments and a teacher's manual. In the afternoon we presented a workshop that described the components and went over each of the experiments.

Based on the feedback from the teachers at these workshops the experiments and teacher's manuals were refined over a number of years. We were continually asked by the teachers when they could buy the kits, but we had no idea when we would be able to sell them. The production of the kits eluded us. My colleagues and I were college professors, not marketing persons. Soon after the Education Committee of OSA was elevated to the status of a Council, an Engineering Council was created. This council was intended to provide closer contacts for OSA with those members in the applied optics areas. The benefit to the Optics kit project was that a gentleman by the name of Paul Forman was assigned as liaison between the Education and Engineering Councils. Paul, who has his hands full as president of Zygo Corporation, was enthusiastic about the kits. Despite his busy schedule he took it upon himself to investigate their use and distribution. After a visit to the National Science Teachers Association (NSTA) convention, Paul came back with a number of ideas and suggestions. He generated a marketing plan to move cautiously toward the manufacture and distribution of the kits. Based on feedback from our OSA Summer Fellows, it we felt that there should be a classroom package. Using some slight fuzzy arithmetic, we decided that a set of 16 kits would be sold together with a teacher's 


\section{\begin{tabular}{|l|l|}
\hline EXPERIMENT \#5 & FRESNEL (Freh-Nell') LENS \\
\hline
\end{tabular}}

EQUIPMENT: Fresnel Lens, Lenses A, B and C, Ruler and White card

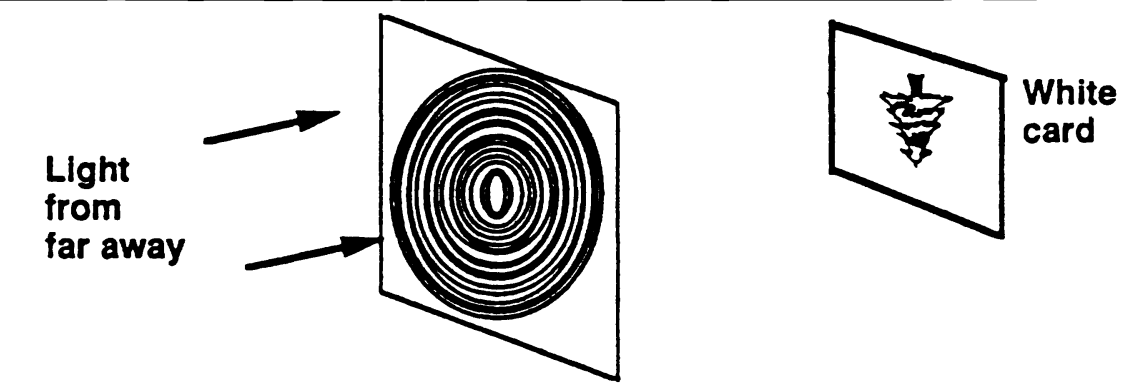

\section{CAUTION! DO NOT LOOK AT THE SUN!}

COMPARE Look closely and carefully at the Fresnel lens.

LENSES 1) Tell how the Fresnel lens itself appears different from the other lenses.

2) Is the Fresnel lens a magnifier? (Look back to Experiment \#2 if you have forgotten how to tell.)

FIND THE In Experiment \#1 you found the focal lengths of some of the lenses.

FOCAL Using a small, bright object (such 25 a light bulb) which is very far

LENGTH from the Fresnel lens, and the white card, find the focal length of the lens.

3) What is the focal length of the Fresnel lens?

MAKE A The Fresnel lens can be used along with one of the other lenses to make TELESCOPE a telescope (see Experiments \#3 and \#4). Choose one of the other lenses and make a telescope.

4) Figure out which type of telescope (Galilean or Keplerian) you have made and explain how you know.

HOW IS THIS The Fresnel lens is a "skinny" lens. Only one

USEFUL? side of the lens is curved. This side is made up of a series of rings each of which has a curvature that is the same as the curve of a regular lens with the same focal length. The Fresnel lens is often used where a big lens that is light in weight is needed, for instance in lighthouses.

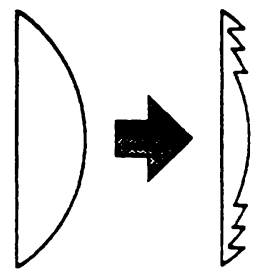

O1988 Optical Society of America

Fig. 2. One of 11 experiment pages in the Classroom Kit. All material for the student is contained on one page. The format is similar to one used with exhibits at the Exploratorium science teaching museum in San Francisco. 


\section{EXPERIMENT \#5 FRESNEL LENS NOTES ON SET-UP}

EXPECTED RESULTS

The Fresnel lens is flat and mounted onto a rectangular piece of clear plastic. The lens appears to have faint circular lines on it. These are the grooves shown in the picture of a Fresnel lens at the bottom of the page in the student experiment. If you look very carefully at an edge view of the lens with a magnifier, you can see the grooves and how their slant changes. If you do not have a window in your classroom, you will need a light bulb for the focal length determination.

\section{Compare lenses}

1) The lens itself has a bigger diameter. It is thin and flat. It has lines in it.

2) Yes, it is a magnifier (its magnification is about 4).

3) The focal length is about $7.5 \mathrm{~cm}$ (3 in).

4) Any of the following combinations will work: Lens $C$ near eye, Fresnel beyond makes a Galilean telescope. Lens B near eye, Fresnel beyond makes a Keplerian telescope. Fresnel near eye, Lens A beyond makes a Keplerian telescope. If the image is right-side up, it is Galilean; if the image is upside-down, it is Keplerian.

All other combinations involving the Fresnel lens produce smaller images and are therefore not telescopes.

1) Which of the other lenses does the Fresnel lens most behave like? It behaves most like lens $\mathrm{A}$. It is a magnifier, it can project images onto a card, and it has about the same focal length.

2) When is a Fresnel-type of lens a better choice to use than a regular type of lens?

It would be better when a large lens is needed. An ordinary large lens is often thick and heavy but the Fresnel lens remains relatively thin and light in weight.

ADDITIONAL

- Have students investigate to find out where Fresnel lenses are used. (Some examples are: in overhead projectors, in traffic lights.)

- Have students find out how different types of lenses are manufactured (molded, ground, cut?).

Fig. 3. An example of the Teacher's Guide instructions that are part of the Classroom Kit, 
manual and one loose leaf set of experiments that teachers could copy and hand out at the time that a particular experiment was done. This became known as the Classroom Kit.

Perhaps the most important rule for the OSA kit was that it be as inexpensive as possible. Our initial target prices was a single kit for $\$ 10$ or less and a classroom kit for $\$ 99$. The latter price was set because many teachers told us that purchase approval was much easier if it cost under $\$ 100$. Paul ran a number of scenarios that would enable us to take an initial run of 5000 kits and try them in a number of markets: previous Educators' Day participants, science museums, NSTA conference sales, and direct mail order. The costs for the ratio of single kits to classroom kits were computed. We ordered our parts and made our plans. The course of such project never seems to run smooth. As part of the kit manufacturing we had to get it out of Baggies. The Society contracted with a firm to design a package for the classroom kit. After a lengthy process the design firm came up with some excellent illustration, some of which are used on the kits, and a price of more that $\$ 40$ for the package for the classroom kit. Paul took one look at the price and we did a complete revision of our classroom kit packaging. The expensive package was replaced by a neat cardboard box the size of a large book with the design firm's illustrations on it. And inside, each of the components packaged as 16 pieces in plastic bags. The single kit package design was also a model of utility. Given that there was no particular size restriction, the box was designed to fit inside a mailer for compact disks. This kept the cost of mailers for the single kits to a nickel (\$0.05). The size of the single kit packaging dictated a new format for the experiments, so I reorganized the material for each experiment onto four 4.5 "x 5" $(11.5 \mathrm{~cm} \times 12.5 \mathrm{~cm})$ pages using my versatile Macintosh. An example of a single kit experiment is shown in Fig.4.

Once the packaging was ready I made up some order forms on my Mac and took some of the first boxes down to booth of the American Institute of Physics at the NSTA meeting that was being held downtown in Atlanta. The response to the kits was excellent according to the AIP staff at the booth. Shortly thereafter, Paul took some kits to a local OSA section meeting in his area. Those who were there bought all the kits he had and ordered more. The response was so strong and positive that we felt that we should relinquish our cautious marketing plan and sell to whoever wanted to buy. Now the problem was how to anticipate the demand and have kits ready when the first run was used up. So the OSA Optics Discovery Kit was launched successfully.

\section{CURRENT STATUS}

Once the kit was launched, we had to determine how large our next run would be. It was decided among the members of the resource committee in consultation with Paul to request funding to make 10,000 kits. It should be understood that the OSA Optics kits are intended to pay their own way. This means that the costs are sufficient to pay for all components, packaging, and distribution. Any "profit" is plowed back into the kit program. The program is intended to be selfsustaining. In stating this I must acknowledge that without the donations and reduced prices from our benefactors, there would be no way that a kit could be assembled for such a price. But even inflation takes its toll and the price on a single kit had to be raised to $\$ 12$ for members of OSA and $\$ 15$ for the general public. The classroom kit now costs $\$ 130$.

Of the 15,000 kits either assembled or authorized about half have been sold. Some sales come through mail order requests, some at OSA booths at optics conventions. The kits have been the centerpiece of a number of educational activities by local sections and student chapters of OSA. Several of my colleagues in graduate research use the kits with their classes, so it isn't just a kid's kit. I was proud to learn that Charles Townes, who was the advisor of my mentor, Herman Cummins, and therefore my "academic grandfather," purchased two kits. But what probably gives me the greatest satisfaction is that the kit is now advertised and sold in the Edmund Scientific catalog with all profits going to OSA. In a way I find that fitting. Edmund's optical junk was responsible for a number of people going into optics and this, in a way, continues the tradition.

The kit has been used in the development of new curriculum in the public schools of Chattanooga, Tennessee and the new Tennessee state curriculum. ${ }^{1}$ I am glad to see these are being used in exploring and investigating activities. I was also pleased that teachers who use the kit were impressed by its compactness. The quarter-inch rule is vindicated. There was, however, one teacher at a workshop that objected to the fact that the components were too small and that the kids would steal them. My response to that was: Any kid who will steal a lens is a potential future optical engineer. 


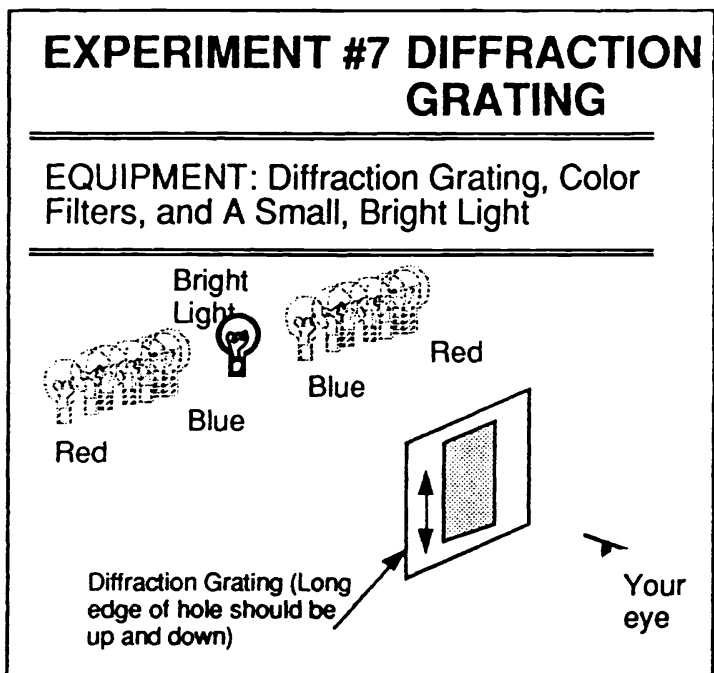

\section{Some Answers}

\section{SPLIT LIGHT INTO A SPECTRUM}

1) On both sides of the light bulb, starting with the color closest to the bulb, the order is blue, green, yellow, orange, red. 2) A fluorescent light may contain some violet before the blue. The colors seen in other sources will depend on what the sources are.

3) Different kinds of lights may have less of or be missing some colors, but whatever colors are there should stay in the samc order as they were in the first light observed.

\section{USE COLOR FILTERS}

4) Red filter- removes (blocks) blue, green, maybe part of yellow; allows through, red, orange, and some yellow.

Green filter- removes red, orange, and part of blue; allows through, yellow, green, and some blue.

Blue filter-removes most of red, orange, and yellow; allows through blue and green.

Yellow filter- removes some of blue; allows through, red, orange, yellow, and green.

\section{Things To Do}

\section{SPLIT LIGHT INTO A SPECTRUN}

It is possible to make light separate into a band of colors (called a SPECTRUM) by shining it through a DIFFRACTION GRATING. A diffraction grating is a rather ordinary looking piece of plastic which actually has thousands (!) of straight grooves lined up across its surface. They are too thin and close together to see even if you use one of your magnifiers. Hold the grating close to your eye and look through it at a small bright light (not the sun). If you have the grating turned so that the grooves run up and down, you should be able to see a spectrum when you look off to either side of the light source. It helps if the rest of the room is fairly dark. If you cannot find the spectrum, try turning the grating to be sure that its grooves are running up and down.

1) Write down all the colors you see in order. Try to look at some different kinds of lights, if available, such as neon lights, fluorescent lights, or street lights.

2) Record all of the colors you see in the spectrum of each type of light source.

3) Are all of the same colors present in the spectrum of different light sources?

\section{USE COLOR FILTERS}

A color filter only lets certain colors of light come through it. Put one of the color filters in front of the diffraction grating. Look through at the light source you first used in this experiment to again see the spectrum. Take the filter away and then put it back. 4) Make two lists: one of the colors which do come through the filter, and one of the colors which are blocked by the filter so that they cannot come through. Put some of the filters together and see if you can predict the colors you will see through the grating.

\section{How Is This Useful?}

When materials reflect or are made to give off light, the colors present in the spectrum of that light are unique to that material. Scientists attempt to match the color pattern from an unknown material to the pattern of a known material. This process, known as SPECTROSCOPY, can be used in many ways. It can be used to find out what stars are made of without going there! It can help solve crimes by showing that material at a crime scene matches material belonging to a suspect.

Fig. 4. Experiment pages for the Single Kit. The pages have been rearranged to provide the correct sequence. In the kit they are printed in a folded, four-page format. 
Science museums and education organizations in a number of other countries have expressed interest in translating the experiments into their language and distributing it. This would be a great way to extend the use of the kit. Those interested should contact the Technical Activities Manager at OSA.

One item that keeps coming back like a bad dream is the use of a videotape to be used as a teaching resource for the optics kit. I have seen three efforts now and none have been effective. The concept has a Catch 22 air to it. If the kits and obviously the videos are going to be inexpensive enough to produce so that teachers can buy them, you cannot spend much money to make a video. But to make a decent video, it is a necessary, but not sufficient, condition, that you must spent a substantial amount of money. To get the video made some proposals try to justify the costs by adding a section, such as Careers in Optics, to the original training section. But this additional section, which must look even better than the training tape, escalates the cost further. Frankly, I think there are enough enthusiastic resource people in OSA who know enough basic optics to be able to serve as initial resource personnel. Good teachers will take over from there.

\section{FUTURE EFFORTS}

With this optics kit as a model, the Resource Committee of OSA has a number of other efforts in the planning stage. One would be a high school optics kit that would take advantage of the small visible light diode lasers that are now available. This kit would be more specifically tied to a curriculum than the Discovery kit. It would however, provide information and instructions on a number of experiments in light sources and detection using the student experiment sheets and teachers manual format developed for the Discovery kit. The emphasis would be directed toward current and future optical technology. Some other kits under consideration would be one on vision and a demonstration kit that uses overhead projectors. This latter project has been proposed by Dr. Douglas Goodman of IBM.

In conjunction with the effort to use the resources available through local chapters, an Optics Suitcase project is being expanded to a national bases. For many years several of the local sections, especially the New England section of OSA has had a suitcase of optics that any member could check out and demonstrate at a school. This effort is part of an effort to assist our members to transfer the enthusiasm they have about optics to their daughters and sons and their classmates.

These days Japanese optics doesn't fall apart as it did when I was a kid, they just produce beautiful pictures. Where are the children of this age of technology going to get the optics to play with? We hope the the OSA Optics Discovery kit is one source for putting optics into the hands of curious children.

\section{ACKNOWLEDGEMENTS}

I would like to thank Paul Forman of Zygo Corporation for taking an interest in the kit and getting it in production. I also thank my colleagues on the Education Council who provided a number of helpful suggestions. Especially encouraging were the my fellow chairs of the Council: Bob Massof, John Walkup, and the current chair, John Wharton.

The suppliers have been instrumental in our ability to control the costs of the kits. They were mentioned in the article, but I would like to acknowledge their participation. I want to thank Robert Edmund, President of Edmund Scientific, for placing the kit in the Edmund catalog.

And while all of us Education Council types go off to work at our normal jobs, the kits demand attention: items to be ordered, requests from other countries, kits to be assembled. All of this is handled with enthusiasm and good humor by the Technical Activities Manager of OSA, Evelyn Roberts. She has contributed as much to the success of the OSA Optics Discovery kits as anyone.

I am grateful to all of those at OSA who gave me the opportunity to develop the kit. The opinions expressed in this article are mine alone and not those of the OSA.

\section{REFERENCES}

1. D. M. Berry, "Quality hands-on activities for discovering science," Optics and Photonics New, vol. 2, June 1991. 